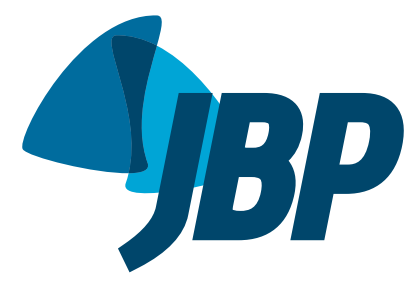

\title{
Melatonin effects on pulmonary tissue in the experimental model of Hepatopulmonary Syndrome
}

Adriane Dal Bosco ${ }^{1, a}$, Filipe Boeira Schedler ${ }^{2, b}$, Josieli Raskopf Colares ${ }^{2, c}$, Elisângela Gonçalves Schemitt ${ }^{2,3, \mathrm{~d}}$, Renata Minuzzo Hartmann ${ }^{2,3, \mathrm{e}}$, Luiz Alberto Forgiarini Junior ${ }^{4, f}$, Alexandre Simões Dias ${ }^{2,3,9}$, Norma Possa Marroni ${ }^{2,3, \mathrm{~h}}$

1. Centro Universitário Metodista, Porto Alegre (RS) Brasil.

2. Hospital de Clínicas de Porto Alegre, Porto Alegre (RS) Brasil.

3. Universidade Federal do Rio Grande do Sul, Porto Alegre (RS) Brasil.

4. Universidade LaSalle, Canoas (RS) Brasil.

a. (iD) http://orcid.org/0000-0003-0907-8325

b. (iD http://orcid.org/0000-0002-5518-2601

c. (D) http://orcid.org/0000-0002-0482-204X

d. (iD http://orcid.org/0000-0003-3015-0192

e. (D) http://orcid.org/0000-0001-8667-517X

f. (ID) http://orcid.org/0000-0002-6706-2703

g. (D) http://orcid.org/0000-0002-0609-4779

h. (D) http://orcid.org/0000-0001-7856-7953

\begin{abstract}
Objective: To evaluate the pulmonary alterations of animals with Hepatopulmonary Syndrome (HPS) submitted to Biliary Duct Ligature (BDL), as well as the antioxidant effect of Melatonin (MEL). Methods: Sixteen male Wistar rats, divided into four Sham groups: BDL group, Sham + MEL group and BDL + MEL. The pulmonary and hepatic histology, lipoperoxidation and antioxidant activity of lung tissue, alveolar-arterial O2 difference and lung / body weight ratio (\%) were evaluated. Results: When comparing the groups, could be observed an increase of vasodilation and pulmonary fibrosis in the $\mathrm{BDL}$ group and the reduction of this in relation to the BDL + MEL group. It was also observed significant changes in the activity of catalase, $\mathrm{ApCO} 2, \mathrm{ApO}_{2}$ in the LBD group when compared to the other groups. Conclusion: The use of MEL has been shown to be effective in reducing vasodilation, fibrosis levels and oxidative stress as well as gas exchange in an experimental HPS model.
\end{abstract}

Keywords: Bile duct; Hepatopulmonary Syndrome; Melatonin; Lung.

Submitted: 18 May 2017

Accepted: 12 August 2018

Study carried out in the Hospital de

Clínicas de Porto Alegre,

Porto Alegre (RS) Brasil.

\section{INTRODUCTION}

The Cirrhosis is presented in the presence of fibrotic nodules in the liver that arise as a result of chronic liver injury. ${ }^{(1)}$ Such alterations can lead to portal hypertension and terminal liver disease, which generate alterations in the vascular system and affecting different organs. ${ }^{(2)}$ In the respiratory system, Hepatopulmonary Syndrome (HPS) and Portopulomonar Hypertension are the two main clinical conditions that affect the lungs. ${ }^{(2)}$ Hepatopulmonary Syndrome is the most common vascular disorder found in patients with cirrhosis, which is responsible for pulmonary vasodilation, hyperdynamic circulation and changes in gas exchange. ${ }^{(2,3)}$

Abnormalities in gas exchange presented by HPS patients are associated with the presence of arteriovenous shunts, ventilation-perfusion discrepancies and diffusionperfusion. (2) These changes present in HPS are mostly explained by intra-pulmonary ${ }^{(2)}$ vasodilatation and angiogenesis, and different animal models are used to simulate hepatic cirrhosis, and the Biliary Duct Ligature (BDL) model best simulates the present alterations in the syndrome. ${ }^{(4)}$
The BDL model is capable of causing gastric changes similar to those found in $\mathrm{HPS}^{(2)}$ patients. The angiogenesis process is also present in the BDL model, that is the an alteration present due to the action of the Vascular Endothelial Growth Factor-A (VEGF-A), which is produced by intravascular pulmonary monocytes. ${ }^{(5,6)}$ Pulmonary vasodilation in the HBL experimental model is associated with increased production of Endothelin-1 (ET-1) and Endothelial Nitric Oxide Synthase (eNOS). ${ }^{(6)}$

Recent studies that investigate the therapeutic potential of Melatonin (MEL) suggest that its antioxidant power can be used in the treatment of HPS, since it has an anti-inflammatory effect ${ }^{(7)}$ and reduces VEGF levels in hepatic carcinoma cells, contributing to the reduction of angiogenesis. ${ }^{(8)}$ Melatonin also has therapeutic effects in animal models of fulminant hepatitis and pulmonary hypertension, reducing oxidative stress and preventing the reduction of the activity of antioxidant enzymes. ${ }^{(9-11)}$ In lung tissue, Melatonin exerts protective effect in animal models of cirrhosis induced by carbon tetrachloride. ${ }^{(12)}$

Due to the existence of an experimental model that simulates HPS and the potential therapeutic effect of 
Melatonin in this syndrome, this study aims to evaluate the pulmonary alterations of animals submitted to Biliary Duct Ligature, as well as the antioxidant effect of Melatonin.

\section{METHODS}

In this study 16 male Wistar rats were used, weighing $250 \mathrm{~g}$ on average. The animals were obtained by the vivarium of University of Brazil Lutheran (ULBRA) and were housed in plastic boxes $(47 \times 34 \times 18 \mathrm{~cm})$ covered with wood shavings, which was stored in a controlled environment with a temperature between 20 and $25^{\circ} \mathrm{C}$. The animals were kept in a light / dark cycle of 12 / $12 \mathrm{~h}$, with free availability for water and food. The research project was previously approved by the ULBRA Ethics Committee for Animal Use (ECAU-ULBRA), and all research procedures are in accordance with the rules established by Law Number 11,794 of October 11, 2008 and by the Guideline Brazilian Association of Practice for the Care and Use of Animals for Scientific and Educational Purposes.

The procedure of Common Bile Duct Ligature (CBDL) was used for the development of HPS, according to the one recommended by Kountouras et al.(13) Prior to all surgical procedures, the animals received an anesthetic dose of Xylazine $2 \%$ (50mg / kg body weight) and Ketamine (100mg / kg body weight), both injected into the intraperitoneal region. The period for the development of the model was 14 days, followed by another 14 days for the treatment with melatonin. The total period of experiment was 28 days, and at the moment of euthanasia, the animals received a dose three times higher than the one used for the surgical procedure.

Four groups ( $n=4)$ were used in the study: Sham group: A simulated CBDL surgical procedure was performed, manipulation of the bile duct with the anesthetized animal and the animals also received intraperitoneal injection of $\mathrm{NaCl}(0.9 \%)$ as on the 15th day after surgery, for 14 days. Sham+Melatonin Group (Sham + MEL): The surgical procedure for CBDL was simulated, and administration of Melatonin (20mg / $\mathrm{kg}$ ) took places by intraperitoneal injection for 14 days, starting on the 15th day after surgery. Biliary Duct Ligature Group (BDL): The animals were submitted to $\mathrm{CBDL}$ and $\mathrm{NaCl}$ application (0.9\%) intraperitoneally for 14 days, starting on the 15th day after surgery. Biliary Duct Ligature Group + Melatonin (BDL + MEL): The animals were submitted to $\mathrm{CBDL}$ and received Melatonin $(20 \mathrm{mg} / \mathrm{kg}$ ) by intraperitoneal injection for 14 days, starting on the 15th day after surgery.

The laboratory tests were performed at the Laboratory of Clinical Analyzes of the Hospital of Clinics of Porto Alegre (HCPA - Laboratório de Análises Clínicas do Hospital de Clínicas de Porto Alegre), and the other analyzes and procedures were performed at the Laboratory of Experimental Hepatology of the Hospital of Clinics of Porto Alegre (HCPA - Laboratório de
Hepatologia Experimental do Hospital de Clínicas de Porto Alegre).

After 28 days after surgery, the animals were weighed and anesthetized and blood was collected through the Retro-Orbital Bleeding Collection Technique, ${ }^{(14)}$ with the objective of analyzing liver enzyme levels. Subsequently, an anteromedial laparotomy was performed to collect blood from the abdominal aorta for gas analysis, using an ABL 700 Radiometer (Copenhagen, Denmark) for the measurement of blood gases. The iontophoresis method was used to measure the Partial Arterial Oxygen Pressure (ApO2), Partial Arterial Carbon Gas Pressure (ApCO2) and Arterial Oxygen Saturation ( $\mathrm{SaO} 2$ ). Alveolar Oxygen Pressure (APO2) was calculated by the following formula: APO2 = Inspired fraction of $\mathrm{O} 2$ (FiO2) -ApCO2 / 0.8. ${ }^{(15)}$ The Alveolar-Arterial Oxygen Difference ( $D(A-a) 02$ ) was calculated by the formula: $\mathrm{D}(\mathrm{A}-\mathrm{a}) \mathrm{O} 2$ = APO2-ApO2.(15)

After euthanasia, the lung was weighed for later analysis of the Pulmonary Weight / Body Weight relation. A portion of the liver and lower right lung lobe was removed for histological analysis, the remainder of the lung tissue introduced into liquid Nitrogen and stored at $-80^{\circ} \mathrm{C}$ for further analysis. Pulmonary and hepatic samples collected for histological analysis were inserted in $10 \%$ formaldehyde solution for 12 hours, and later inserted in $70 \%$ alcohol containers and stained with Hematoxylin and Eosin (HE) staining, the pulmonary samples were also stained of picrosirius. The histological analyzes were performed in a blinded experiment manner by specific pathologists from the HCPA Pathology Laboratory.

Frozen lung tissue was homogenized by an Ultra-Turraz homogenizer (IKA Labortechnik, Staufen, Germany) in phosphate buffer (140 mM KCl, $20 \mathrm{nM}$ Phosphate, $\mathrm{pH}$ 7.4). The lipoperoxidation was measured by the technique of substances that react to Thiobarbituric Acid (TBARS). ${ }^{(16)}$ The activities of the enzymes Catalase (CAT) and Glutathione-S-transferase (GST) were measured through the Spectrophotometer. ${ }^{(17,18)}$

Averages and Standard Deviations (SD) were calculated. The data were analyzed by Analysis of Variance (ANOVA) followed by Tukey post hoc test. Values were considered significantly different when $p$ $<0.05$. Statistical Package for Social Sciences software (SPSS Inc., Chicago, IL, USA) version 21.0 was used.

\section{RESULTS}

The analysis of the liver enzymes activity and liver histology confirmed the diagnosis of Cirrhosis. In Figure 1 , it can be seen from the pulmonary histological analysis that the animals of the BDL group presented vessels with increased diameters in relation to the other groups. Since the findings in each group are very similar, only one histological example will be presented for each experimental group.

In Table 1, the results regarding changes in gas exchange through Arterial blood gas test, with values referring to $\mathrm{ApO} 2, \mathrm{ApCO} 2, \mathrm{SaO} 2, \mathrm{APO} 2$ and $\mathrm{D}(\mathrm{A}-\mathrm{a})$ 
O2 can be observed, being compared among the four experimental groups. Significant differences were found for $\mathrm{ApCO} 2$ and $\mathrm{APO}$, and the values for the BDL group were significantly increased and decreased, respectively, in relation to the other groups $(p<0.05)$. The Table 2 also shows a significant increase $(p<0.01)$ ratio lung weight / body weight in the BDL group compared to the other experimental groups.

Intrapulmonary vasodilation associated with gastric abnormalities confirms the experimental HPS model. The decrease in intrapulmonary vasodilation, $\mathrm{ApCO} 2$ and pulmonary / body weight ratio in the BDL + MEL group, as well as the increase of APO2 in relation to $B D L$, which suggest a protective effect of MEL in the pulmonary tissue before HPS.
The Table 1 shows results regarding the lipoperoxidation process and activity of the antioxidant enzymes characterized by TBARS, CAT and GST values. The increased values of TBARS in the BDL group compared to the other groups $(p<0.01)$ indicate an increase in lipoperoxidation in this experimental group. The CAT activity was significantly lower in the BDL group ( $p<0.01$ ), while GST activity in the BDL group was significantly increased in relation to the other groups. The BDL + MEL group presented lower results for the TBARS values in relation to the BDL group, indicating an antioxidant effect of MEL.

In Figure 2, an increase in pulmonary fibrosis, marked by red staining, was found in the BDL group in relation to the other groups. This process was reversed with

Table 1. Blood gases, alveolar-arterial oxygen gradient, and lung / body weight ratio in the four experimental groups. ${ }^{\mathrm{a}}$

\begin{tabular}{lcccc}
\multicolumn{1}{c}{ Variable } & Sham & Sham + MEL & BDL & BDL + MEL \\
$\mathrm{ApO}_{2}$ & $67 \pm 11.3$ & $66.3 \pm 12.4$ & $57.2 \pm 6.2$ & $71 \pm 5.4$ \\
$\mathrm{ApCO}_{2}$ & $45 \pm 1.4$ & $48 \pm 5.2$ & $56.6 \pm 1.5^{*}$ & $48.2 \pm 4.5$ \\
$\mathrm{SaO}_{2}$ & $91 \pm 4.2$ & $88.3 \pm 6.4$ & $84.8 \pm 6.2$ & $92.5 \pm 2.6$ \\
$\mathrm{APO}_{2}$ & $93.4 \pm 1.7$ & $89.7 \pm 6.6$ & $78.9 \pm 1.9^{*}$ & $89.4 \pm 5.7$ \\
$\mathrm{D}(\mathrm{A}-\mathrm{a}) \mathrm{O}_{2}$ & $26.4 \pm 13$ & $23.4 \pm 5.9$ & $21.7 \pm 5.7$ & $18.4 \pm 11$ \\
Pulmonary weight ratio/ body weight (\%) & $0.32 \pm 0.09$ & $0.34 \pm 0,05$ & $0.57 \pm 0.05^{* *}$ & $0.37 \pm 0.02$ \\
\hline
\end{tabular}

BDL: Biliary Duct Ligature; Sham+MEL: Sham and melatonin; BDL+MEL: Biliary Duct Ligature and melatonin. $\mathrm{ApO}_{2}$ : Arterial Partial Oxygen Pressure; $\mathrm{ApCO}_{2}$ : arterial partial pressure of carbon dioxide; $\mathrm{SaO}_{2}$ : arterial oxygen saturation; $\mathrm{APO}_{2}$ : alveolar partial pressure of oxygen; and $\mathrm{D}(\mathrm{A}-\mathrm{a}) \mathrm{O}_{2}$ : alveolar-arterial oxygen gradient. ${ }^{a}$ Results expressed by average + standard deviation. ${ }^{*} p<0.05$ vs. group Sham, Sham + MEL, BDL + MEL. $* * p<0.01$ vs. group Sham, Sham + MEL, HBL + MEL.
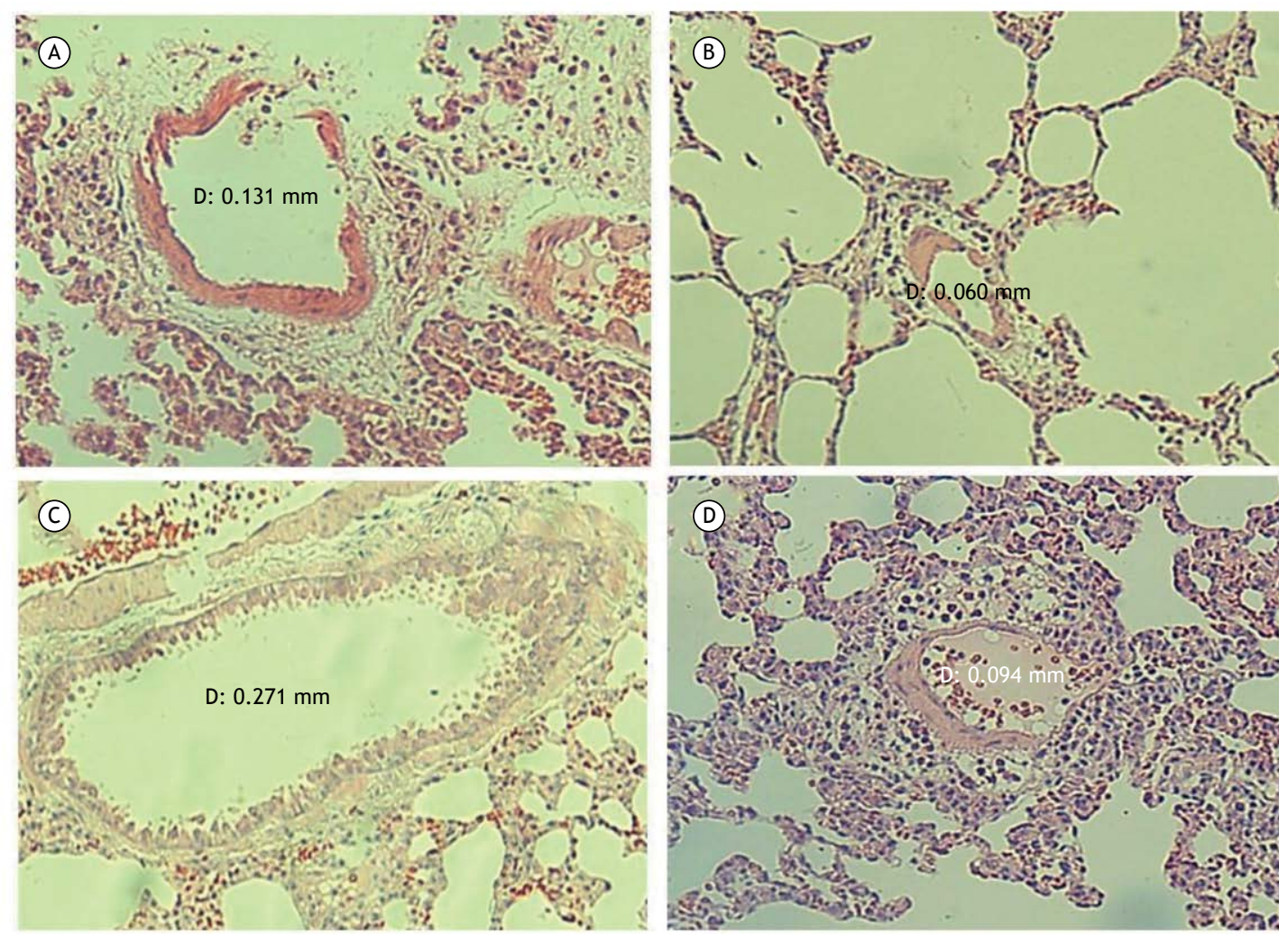

Figure 1. Microscopy images of pulmonary tissue samples stained by hematoxylin and eosin (HE), zoomed 100x. (A) Sham Group; (B) Group Sham and Melatonin; (C) Group Biliary Duct Ligature; (D) Duct Ligature Group Biliary and Melatonin. 
the use of Melatonin, with pulmonary fibrosis being shown to be decreased from the BDL + MEL group in relation to the $\mathrm{BDL}$ group.

\section{DISCUSSION}

The increase in the diameter of the pulmonary vessels, evidenced by the histological analysis by hematoxylin and eosin (HE), in association with the gasometrical alterations, confirms in the present study the induction of HPS through the BDL surgery. The decrease in the diameter of the pulmonary vessels in the BDL + MEL group compared to the group HBL therapeutic effects of Melatonin suggest the vascular adaptation process.

According to our results, the $\mathrm{ApCO} 2$ increased in BDL group compared to the other groups, while APO2 decreased in the same group. Vercelino et al.(4) also found an increase in PCO2 in the BDL group when compared to the control group, as well as additional alterations in the BDL group, with changes in ApO2, $\mathrm{SaO} 2$ and $\mathrm{D}(\mathrm{A}-\mathrm{a}) \mathrm{O} 2$ values. Several studies associate the gasometrical alterations present in HPS with the action of Nitric Oxide (NO) on lung tissue. ${ }^{(19,20)}$ Tieppo et al. ${ }^{(21)}$ found that the antioxidant action of Quercetin is able to reverse the gasometrical alterations in the HPS experimental model, suggesting that the antioxidant is able to regulate the ON levels in the syndrome. Our results demonstrate that Melatonin improves the gas alterations in the BDL model, as well as reverses intrapulmonary vasodilation, suggesting that Melatonin plays a role similar to that of Quercetin in the regulation of ON levels in HPS.

Vercelino et al.(4) also found an increase in lipoperoxidation and antioxidant activity of the SOD

Table 2. Levels of thiobarbituric acid-reactive substances (nmol / mg protein), antioxidant activity of the catalase enzyme (pmol / min / mg prot.) And glutathione-s -transferase ( $\mathrm{nmol} / \mathrm{min} / \mathrm{mg}$ prot.). ${ }^{\mathrm{a}}$

\begin{tabular}{lcccc}
\multicolumn{1}{c}{ Variable } & Sham & Sham + MEL & BDL & BDL + MEL \\
TBARS (nmol/mg protein) & $0.38 \pm 0.09$ & $0.37 \pm 0.15$ & $0.83 \pm 0.13^{* *}$ & $0.5 \pm 0.08$ \\
CAT (pmol/min/mg protein) & $8.32 \pm 1.27$ & $9.09 \pm 1.01$ & $5.17 \pm 0.72^{* *}$ & $8.52 \pm 1.14$ \\
GST (nmol/min/mg protein) & $2.54 \pm 1.05$ & $2.08 \pm 1.09$ & $7.78 \pm 1.22^{* *}$ & $3.95 \pm 1.99$ \\
\hline
\end{tabular}

TBARS: thiobarbituric acid reactive substances; CAT: catalase; GST (glutation-s-transferase). BDL: Biliary Duct Ligature; Sham+MEL: Sham e melatonin; BDL+MEL: Biliary Duct Ligature and melatonin. aResults expressed by average + standard deviation. ${ }^{* *} \mathrm{p}<0.01$ vs. group Sham, Sham + MEL, BDL + MEL.
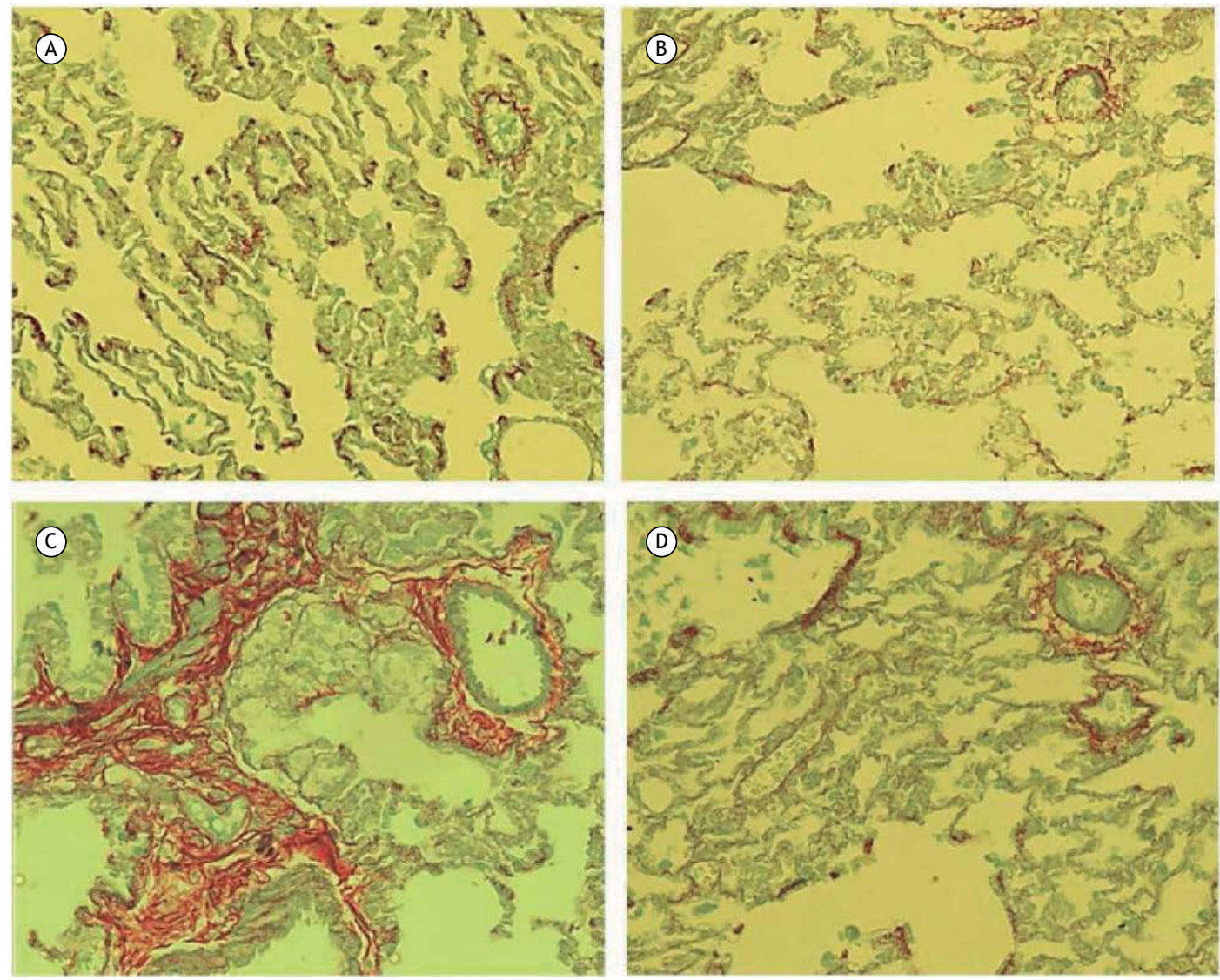

Figure 2. Microscopy images of the pulmonary tissue samples stained by picrosirius, zoomed of 100x. (A) Sham Group; (B) Group Sham and Melatonin; (C) Group Biliary Duct Ligature; (D) Duct Ligature Group Biliary and Melatonin. 
enzyme in lung tissue in the BDL group, as well as an increase in lung weight / body weight ratio in animals submitted to BDL surgery, matching with the results in the present study. Maarman et al. ${ }^{(11)}$ found an increase in lung weight and a decrease in body weight in the experimental model of Pulmonary Hypertension, which was reversed by the use of Melatonin. Similarly, as in this study, Melatonin was able to decrease the lung / body weight ratio.

There was an increase in lipoperoxidation in the BDL group and consequent reversal after administration of Melatonin. A decrease in CAT activity and an increase in GST activity were found in the BDL group, which were reverted by the use of Melatonin. The increase of oxidative stress in the body and consequent lipoperoxidation is due to the imbalance between the presence of free radicals and antioxidant agents. ${ }^{(22)}$ Although several results on the activity of CAT and GST antioxidant enzymes are found in the literature, the results of this study demonstrate a decrease in lipoperoxidation and an improvement in the antioxidant system after the use of Melatonin.

Several studies associate the use of Melatonin with the reduction of lipoperoxidation, however the activity of antioxidant enzymes with the use of Melatonin presents diverse results. ${ }^{(11-14)}$ Maarman et al. ${ }^{(11)}$ found a decrease in the activity of SOD and CAT enzymes and plasma lipoperoxidation in animals with Pulmonary Hypertension treated with Melatonin. Taslidere et al. ${ }^{(12)}$ associate the use of Melatonin with decreased lipoperoxidation and increased activity of CAT and Glutathione (GSH) enzymes in rat lung tissue after cirrhosis induced by Carbon Tetrachloride (CCl4). Borges et al. ${ }^{(23)}$ demonstrate that the use of Melatonin decreases muscle lipoperoxidation generated by vigorous exercise, as well as increases SOD activity, but there are no significant changes in CAT and Glutathione Peroxidase (GPx) activity. Similarly, Rosa et al. ${ }^{(24)}$ demonstrated that Melatonin decreases lipoperoxidation and increases SOD activity in the liver of animals submitted to the experimental Sleep Apnea model.
The results of this study, obtained through the histological analysis by picrosirius, suggest that Melatonin was able to reduce the accumulation of pulmonary collagen (Figure 2). Maarman et al. ${ }^{(11)}$ found a decrease in collagen in cardiac tissue after the use of Melatonin in the model of Pulmonary Hypertension, and Rosa et al. ${ }^{(25)}$ found a reduction of hepatic collagen after the use of Melatonin in the experimental model of cirrhosis by $\mathrm{CCl} 4$.

The Melatonin's antioxidant activity in liver and lung tissue is associated with the reversal of the main changes in the HPS. This therapeutic effect of melatonin may occur by a direct improvement in antioxidant activity in the lung, or simply by improving liver condition, reversing the systemic changes in the disease. The physical exercise also exerts a decrease in oxidative stress and an increase in antioxidant activity in a systemic way. Since cirrhosis and HPS affect different organs, therapeutic interventions that act on the different body systems are potentially more indicated for the management of the pathology. Therefore, the Melatonin use and the physical exercise practices, associated with traditional and drug interventions well established, may in the future help patients affected by the disease.

This study presents a possible limitation of its experimental design, which impairs the direct clinical transposition of the findings to HPS patients. However, it should be pointed out that the BDL model is the best experimental model for the study of HPS because it promotes true cirrhosis and changes all parameters of arterial gas exchange, increase lipoperoxidation and antioxidant defense. ${ }^{(4)}$

The MEL antioxidant action in lung tissue has been shown to be effective in reducing vasodilatation, fibrosis, oxidative stress, as well as improving pulmonary weight / body weight ratio, $\mathrm{PCO} 2$ and $\mathrm{APO} 2$ in the HPS experimental model. These findings suggest an antioxidant effect of MEL on HPS pulmonary damage, being effective in reducing the gasometrical and structural changes caused by the syndrome.

\section{REFERENCES}

1. Schuppan D, Afdhal NH. Liver cirrhosis. Lancet. 2008;371(9615):838-51. http://dx.doi.org/10.1016/S0140-6736(08)60383-9. PMid:18328931.

2. Zhang J, Fallon MB. Hepatopulmonary syndrome: update on pathogenesis and clinical features. Nat Rev Gastroenterol Hepatol. 2012;9(9):539-49. http://dx.doi.org/10.1038/nrgastro.2012.123. PMid:22751459.

3. Grace JA, Angus PW. Hepatopulmonary syndrome: update on recent advances in pathophysiology, investigation, and treatment. J Gastroenterol Hepatol. 2013;28(2):213-9. http://dx.doi.org/10.1111/ jgh.12061. PMid:23190201.

4. Vercelino R, Tieppo J, Forgiarini LAJr, Dias AS, Marroni CA, Marroni NP. Modelos experimentais para avaliação das alterações pulmonares na síndrome hepatopulmonar. J Bras Pneumol. 2008;34(7):453-60. http:// dx.doi.org/10.1590/S1806-37132008000700004. PMid:18695789.

5. Zhang J, Luo B, Tang L, Wang Y, Stockard CR, Kadish I, et al. Pulmonary angiogenesis in a rat model of hepatopulmonary syndrome. Gastroenterology. 2009;136(3):1070-80. http://dx.doi. org/10.1053/j.gastro.2008.12.001. PMid:19109954.

6. Yang W, Zhang J, Hu B, Wu W, Venter J, Alpini G, et al. The role of receptor tyrosine kinase activation in cholangiocytes and pulmonary vascular endothelium in experimental hepatopulmonarysyndrome. Am J Physiol Gastrointest Liver Physiol. 2014;306(1):G72-80. http:// dx.doi.org/10.1152/ajpgi.00178.2013. PMid:24200956.

7. Mauriz JL, Collado PS, Veneroso C, Reiter RJ, González-Gallego J. A review of the molecular aspects of melatonin's antiinflammatory actions: recent insights and new perspectives. J Pineal Res. 2013;54(1):1-14. http://dx.doi.org/10.1111/j.1600079X.2012.01014.x. PMid:22725668.

8. Carbajo-Pescador S, Ordoñez R, Benet M, Jover R, García-Palomo A, Mauriz JL, et al. Inhibition of VEGF expression through blockade of Hif1 $\alpha$ and STAT3 signalling mediates the anti-angiogenic effect of melatonin in HepG2 liver cancer cells. Br J Cancer. 2013;109(1):8391. http://dx.doi.org/10.1038/bjc.2013.285. PMid:23756865.

9. Crespo I, Miguel BS, Laliena A, Álvarez M, Culebras JM, GonzálezGallego J, et al. Melatonin prevents the decreased activity of antioxidant enzymes and activates nuclear erythroid 2-related factor 2 signaling in an animal model of fulminant hepatic failure of viral origin. J Pineal Res. 2010;49(2):193-200. PMid:20609075. 
10. Tuñón MJ, San-Miguel B, Crespo I, Laliena A, Vallejo D, Álvarez M, et al. Melatonin treatment reduces endoplasmic reticulum stress and modulates the unfolded protein response in rabbits with lethal fulminant hepatitis of viral origin. J Pineal Res. 2013;55(3):221-8. http://dx.doi.org/10.1111/jpi.12063. PMid:23679826.

11. Maarman G, Blackhurst D, Thienemann F, Blauwet L, Butrous G, Davies N, et al. Melatonin as a preventive and curative therapy against pulmonary hypertension. J Pineal Res. 2015;59(3):343-53. http://dx.doi.org/10.1111/jpi.12263. PMid:26201290.

12. Taslidere E, Esrefoglu M, Elbe H, Cetin A, Ates B. Protective effects of melatonin and quercetin on experimental lung injury induced by carbon tetrachloride in rats. Exp Lung Res. 2014;40(2):59-65. http:// dx.doi.org/10.3109/01902148.2013.866181. PMid:24447267.

13. Kountouras J, Billing BH, Scheuer PJ. Prolonged bile duct obstruction: a new experimental model for cirrhosis in the rat. $\mathrm{Br} J$ Exp Pathol. 1984;65(3):305-11. PMid:6743531.

14. Halpern BN, Pacaud A. Technique of obtaining blood samples from small laboratory animals by puncture of ophthalmic plexus. C R Seances Soc Biol Fil. 1951;145(19-20):1465-6. PMid:14926151.

15. Ribeiro-Silva A, Silva GAD. Trocas gasosas intrapulmonares sob respiração em ar ambiente em pacientes hipercapneicos. Rev Assoc Med Bras. 2004;50(1):32-6. http://dx.doi.org/10.1590/S010442302004000100031. PMid:15253023.

16. Buege JA, Aust S. D. Microsomal lipid peroxidation. Methods Enzymol. 1978;52:302-10. http://dx.doi.org/10.1016/S00766879(78)52032-6. PMid:672633.

17. Beers RF Jr, Sizer IW. A spectrophotometric method for measuring the breakdown of hydrogen peroxide by catalase. J Biol Chem. 1952;195(1):133-40. PMid:14938361.

18. Habig WH, Pabst MJ, Jakoby WB. The first enzymatic step in mercapturic acid formation. J Biol Chem. 1974;249(22):7130-9. PMid:4436300.

19. Rolla G, Brussino L, Colagrande P, Dutto L, Polizzi S, Scappaticci E, et al. Exhaled nitric oxide and oxygenation abnormalities in hepatic cirrhosis. Hepatology. 1997;26(4):842-7. http://dx.doi.org/10.1002/ hep.510260406. PMid:9328302

20. Nunes H, Lebrec D, Mazmanian M, Capron F, Heller J, Tazi KA, et al. Role of nitric oxide in hepatopulmonary syndrome in cirrhotic rats. Am J Respir Crit Care Med. 2001;164(5):879-85. http://dx.doi. org/10.1164/ajrccm.164.5.2009008. PMid:11549549.

21. Tieppo J, Cuevas MJ, Vercelino R, Tuñón MJ, Marroni NP González-Gallego J. Quercetin administration ameliorates pulmonary complications of cirrhosis in rats. J Nutr. 2009;139(7):1339-46. http:// dx.doi.org/10.3945/jn.109.105353. PMid:19494027.

22. Sánchez $A$, Calpena $A C$, Clares B. Evaluating the oxidative stress in inflammation: role of melatonin. Int J Mol Sci. 2015;16(8):16981 7004. http://dx.doi.org/10.3390/ijms160816981. PMid:26225957.

23. Borges LS, Dermargos A, Silva EP Jr, Weimann E, Lambertucci RH, Hatanaka E. Melatonin decreases muscular oxidative stress and inflammation induced by strenuous exercise and stimulates growth factor synthesis. J Pineal Res. 2015;58(2):166-72. http://dx.doi org/10.1111/jpi.12202. PMid:25546615.

24. Rosa DP, Forgiarini LF, Silva MB, Fiori CZ, Andrade CF, Martinez D et al. Antioxidants inhibit the inflammatory and apoptotic processes in an intermittent hypoxia model of sleep apnea. Inflamm Res. 2015;64(1):21-9. $\quad$ http://dx.doi.org/10.1007/s00011-014-0778-5. PMid:25380745

25. Rosa DP, Bona S, Simonetto D, Zettler C, Marroni CA, Marroni NP. Melatonin protects the liver and erythrocytes against oxidative stress in cirrhotic rats. Arq Gastroenterol. 2010;47(1):72-8. http://dx.doi. org/10.1590/S0004-28032010000100013. PMid:20520979. 